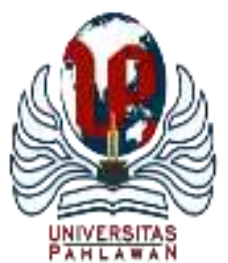

Edukatif : Jurnal Ilmu Pendidikan Volume 3 Nomor 6 Tahun 2021 Halm 5213 - 5219

EDUKATIF: JURNAL ILMU PENDIDIKAN

Research \& Learning in Education

https://edukatif.org/index.php/edukatif/index

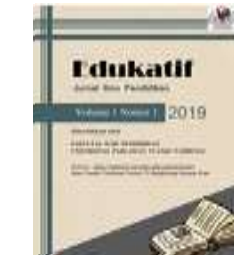

\title{
Pengaruh Model Pembelajaran Numbered Head Together (NHT) terhadap Motivasi Belajar pada Permainan Bola Basket Siswa SMP
}

\author{
Muhammad Ali Hanafiah ${ }^{1}$, Martiani $^{2 凶}$, Citra Dewi $^{3}$
}

Program Studi Pendidikan Jasmani, Universitas Dehasen Bengkulu, Indonesia ${ }^{1,2,3}$

E-mail : alihanafiah296@gmail.com ${ }^{1}, \underline{\text { annie.phaph@unived.ac.id }}^{2}, \underline{\text { citravioleta04@gmail.com }}^{3}$

\begin{abstract}
Abstrak
Penelitian ini bertujuan untuk mengetahui Pengaruh Model Pembelajaran Numbered Head Together (NHT) terhadap Motivasi Belajar pada Permainan Bola Basket Siswa SMP, dengan subjek berjumlah 50 orang dan terdiri dari dua kelas. (kelas eksperimen dan kontrol). Jenis penelitian ini adalah Pre-Experimental design karena desain ini belum merupakan eksperimen yang sebenarnya, dengan teknik pengumpulan data melalui observasi, dokumentasi, dan kuesioner (Angket). Teknik Pengolahan data menggunakan uji t paired sampel. Ditemukan bahwa, motivasi belajar siswa yang menggunakan model pembelajaran Numbered Head Together (NHT) dengan perolehan persentase 72\%, sedangkan motivasi belajar siswa yang menggunakan model pembelajaran konvensional dengan perolehan presentase $56 \%$. Selanjutnya, berdasarkan hasil uji hipotesis dengan menggunakan uji " $t$ " hitung sebesar 2.554 dengan nilai probabilitas (sig) $=0.017<0.05$, yang berarti hipotesis kerja $\left(\mathrm{H}_{\mathrm{a}}\right)$ dalam penelitian ini diterima, yaitu terdapat perbandingan motivasi belajar siswa menggunakan Model Pembelajaran Numbered Head Together (NHT) dengan siswa yang belajar menggunakan model pembelajaran konvensional. Dengan demikian, diperoleh kesimpulan bahwa pembelajaran yang menggunakan Model Pembelajaran Numbered Head Together (NHT) motivasinya lebih tinggi dari pada motivasi siswa yang belajar dengan menggunakan model pembelajaran konvensional.
\end{abstract}

Kata Kunci: Model Pembelajaran Numbered Head Together, Model Pembelajaran Konvensional, Motivasi Belajar.

\begin{abstract}
This study aims to determine the effect of the Numbered Head Together (NHT) learning model on learning motivation in junior high school basketball games, with 50 subjects consisting of two classes. (experimental and control classes). This type of research is Pre-Experimental design because this design is not yet an actual experiment, with data collection techniques through observation, documentation, and questionnaires (Questionnaire). The data processing technique used paired sample t test. It was found that the learning motivation of students who used the Numbered Head Together (NHT) learning model with a percentage acquisition of 72\%, while the learning motivation of students who used the conventional learning model with a percentage gain of 56\%. Furthermore, based on the results of hypothesis testing using the " $t$ " test, it is calculated at 2,554 with a probability value $($ sig $)=0.017<0.05$, which means that the working hypothesis ( $\mathrm{Ha}$ ) in this study is accepted, that is, there is a comparison of students' learning motivation using the Numbered Head Together Learning Model. (NHT) with students who study using conventional learning models. Thus, it can be concluded that learning using the Numbered Head Together (NHT) Learning Model has a higher motivation than the motivation of students who learn using conventional learning models.
\end{abstract}

Keywords: Numbered Head Together Learning Model, Conventional Learning Model, Learning Motivation.

Copyright (c) 2021 Muhammad Ali Hanafiah, Martiani, Citra Dewi

$\triangle$ Corresponding author

Email : annie.phaph@unived.ac.id

DOI : https://doi.org/10.31004/edukatif.v3i6.1655

ISSN 2656-8063 (Media Cetak)

ISSN 2656-8071 (Media Online)

Edukatif : Jurnal Ilmu Pendidikan Vol 3 No 6 Tahun 2021 p-ISSN 2656-8063 e-ISSN 2656-8071 
5214 Pengaruh Model Pembelajaran Numbered Head Together (NHT) terhadap Motivasi Belajar pada Permainan Bola Basket Siswa SMP - Muhammad Ali Hanafiah, Martiani, Citra Dewi

DOI: https://doi.org/10.31004/edukatif.v3i6.1655

\section{PENDAHULUAN}

Menurut (“Undang-Undang Nomor 20 Tahun 2003 Tentang Sistem Pendidikan Nasional,” 2003) Pendidikan sebagai usaha sadar dan terencana. untuk mewujudkan suasana belajar, dan proses pembelajaran agar peserta didik, secara aktif mengembangkan potensi dirinya untuk memiliki kekuatan spiritual keagamaan, pengendalian, kepribadian, kecerdasan, akhlak mulia serta keterampilan yang diperlukan dirinya, masyarakat, bangsa dan negara.

Pendidikan adalah proses dalam rangka mempengaruhi peserta didik agar mampu menyesuaikan diri sebaik mungkin dengan lingkungannya, dengan demikian akan menimbulkan perubahan dalam dirinya yang bermanfaat untuk kehidupan masyarakat. Pengajaran bertugas mengarahkan proses ini agar sasaran dari perubahan itu dapat tercapai sebagaimana yang diinginkan. Pada dasarnya, pertumbuhan dan perkembangan peserta didik bergantung pada dua unsur yang saling mempengaruhi, yakni bakat yang dimiliki oleh peserta didik sejak lahir, dan lingkungan yang mempengaruhi hingga bakat tumbuh dan berkembang.

Sekolah sebagai lembaga pendidikan formal, secara sistematis merencanakan bermacam-macam lingkungan, yakni lingkungan pendidikan yang menyediakan berbagai kesempatan bagi peserta didik untuk melakukan kegiatan belajar. Dengan berbagai kesempatan belajar, pertumbuhan dan perkembangan peserta didik diarahkan dan didorong ke pencapaian tujuan yang dicita-citakan. Lingkungan tersebut disusun dan ditata dalam suatu kurikulum, yang pada gilirannya dilaksanakan dalam bentuk proses pembelajaran (Hamalik, 2018).

Pendidikan jasmani merupakan salah satu mata pelajaran yang mempunyai peranan penting dalam pendidikan secara keseluruhan. Menurut (Saryono \& Rithaudin, 2011) pendidikan jasmani adalah proses pendidikan yang memanfaatkan aktivitas jasmani yang di rencanakan secara sistematik yang bertujuan untuk meningkatkan individu secara organik, neuromuskuler, perseptual, kognitif dan emosional. (Rahayu, 2013) mengemukakan bahwa pendidikan jasmani adalah fase dari program pendidikan keseluruhan yang memberikan kontribusi, terutama melalui pengalaman gerak, untuk pertumbuhan dan perkembangan secara utuh untuk tiap siswa. Pendidikan jasmani didefinisikan sebagai pendidikan dan melalui gerak dan harus dilaksanakan dengan cara-cara yang tepat agar memiliki makna bagi siswa pendidikan jasmani merupakan program pembelajaran yang memberikan perhatian yang proporsional dan memadai pada domain-domain pembelajaran, yaitu psikomotor, kognitif, dan afektif.

Dalam mencapai tujuan pembelajarannya siswa harus memiliki motivasi dalam belajar. Motivasi sangat berperan dalam kegiatan pembelajaran. Karena hasil belajar akan optimal kalau ada motivasi. Motivasi ini yang berfungsi sebagai roda penggerak suatu aktifitas, dalam hal ini yang dimaksud adalah kegiatan belajar. Motivasi yang tinggi akan berpengaruh terhadap perolehan hasil belajar peserta didik sesuai dengan penelitian (Sholihah \& Kurniawan, 2016). Semakin tepat motivasi akan semakin berhasil pula kegiatan belajar siswa, dengan motivasi akan menjadi tempat yang tersendiri.

Motivasi belajar merupakan sebuah energi perubahan yang telah muncul pada diri seseorang dengan adanya perasaan untuk menggapai sebuah tujuan, dengan demikian adanya perubahan pada diri seseorang secara disadari maupun tidak merupakan pertanda adanya motivasi pada diri seseorang (Emda, 2018). Indikator dari motivasi belajar terdiri dari motivasi instrinsik dan motivasi ekstrinsik Cahya dalam (Khunaini \& Sholikhah, 2021). Menurut Gagne dalam (Kurniawan, 2011), motivasi berprestasi merupakan "cara seseorang untuk berusaha dengan baik untuk berprestasi. Motivasi berprestasi memegang peranan penting dalam memberikan gairah, semangat dan rasa senang dalam belajar sehingga mempunyai motivasi tinggi mempunyai energi yang banyak untuk melaksanakan belajar. Siswa yang mempunyai motivasi tinggi sangat sedikit yang tertinggal belajarnyan dan sangat sedikit pula kesalahan dalam belajarnya.

Motivasi diartikan sebagai penyebab terjadinya perubahan tingkah laku yang didorong dengan adanya tujuan, kebutuhan serta keinginan (Sulfemi, 2018). Menurut (Novalinda et al., 2018), motivasi belajar 


\section{Pengaruh Model Pembelajaran Numbered Head Together (NHT) terhadap Motivasi Belajar pada Permainan Bola Basket Siswa SMP - Muhammad Ali Hanafiah, Martiani, Citra Dewi DOI: https://doi.org/10.31004/edukatif.v3i6.1655}

tercermin dari sikap perhatian yang diberikan peserta didik dalam aktivitas belajar, serta memiliki semangat dan tanggungjawab dalam melaksanakan tugas yang diberikan guru. Untuk menumbuhkan dan menghidupkan motivasi belajar dalam diri seorang peserta didik, maka hendaknya siswa mengetahui tujuan belajar itu sendiri serta manfaatnya, apabila dipadukan antara tujuan dan manfaat dengan motivasi sangatlah memungkinkan mereka belajar dan mendapatkan hasil yang baik. Selain mengetahui tujuan belajar, model pembelajaran yang dipilih menjadi salah satu sumber yang berkaitan dengan faktor-faktor lainnya. Model pembelajaran adalah pola atau rancangan yang digunakan dalam merencanakan suatu pembelajaran di kelas (Trianto, 2010). Kerangka konseptual yang mengatur proses belajar siswa secara teratur dan sistematis untuk mengelola pengalaman belajar siswa dan untuk mencapai tujuan belajar yang diinginkan juga disebut sebagai model pembelajaran (Suprihatiningrum, 2013).

Kecermatan guru dalam menentukan model pembelajaran menjadi semakin penting, karena pembelajaran adalah suatu proses yang kompleks yang di dalamnya melibatkan berbagai unsur yang dinamis. Keterlibatan siswa dalam proses belajar pembelajaran merupakan hal yang sangat penting, akan tetapi guru harus tetap dapat mengontrol aktivitas perilaku siswa di kelas, mencermati perbedaan-perbedaan antar siswa serta karakteristik masing-masing individu. Menurut (Aunurrahman, 2014) Untuk mengatasi permasalahan tersebut salah satu upaya peneliti untuk menggunakan penerapan model pembelajaran yang bersifat cooperatif learning akan membantu Guru dan siswa agar pembelajaran menarik dan menyenangkan, untuk mengatasi permasalahan-permasalah tersebut.

Rini \& Mawardi dalam (Hutama et al., 2019) mengungkapkan bahwa penggunaan model kooperatif mampu menjadikan siswa bekerja secara mandiri untuk mencari pengetahuan sendiri dari berbagai sumber belajar di sekitarnya. Tipe model pembelajaran kooperatif yang dapat digunakan adalah model Numbered Head together (NHT). Rahmawati dalam (Hutama et al., 2019), Model Pembelajaran NHT adalah model pembelajaran yang berorientasi kepada siswa. Pembelajaran dikelas yang menerapkan model Pembelajaran NHT dapat menekankan langkah pembelajaran yang interaktif, terutama terhadap antar siswa dalam kelompok kecil.

Adapun langkah-langkah dalam model pembelajaran kooperatif tipe Numbered Head Together, menurut Huda dalam (Gracia \& Anugraheni, 2021) terdapat lima langkah untuk melakukan model pembelajaran kooperatif tipe Numbered Head Together, yaitu : 1) siswa dibentuk dalam kelompok yang beranggotakan empat sampai enam orang siswa, 2) setiap siswa yang sudah berada dalam kelompok diberi nomor, 3) masing-masing kelompok yang sudah dibentuk mendapatkan tugas atau pertanyaan dari guru, 4) setiap kelompok yang sudah diberi tugas atau pertanyaan oleh guru, maka anggota yang berada dalam kelompok tersebut bisa aling berdiskusi untuk menemukan jawaban yang paling tepat dan memastikan semua anggota kelompok mengetahui jawaban tersebut, 5) setelah berdiskusi dan mendapat jawaban yang menurut setiap kelompok benar, guru memanggil salah satu nomor secara acak dan siswa dengan nomor yang dipanggil dapat mempresentasikan jawaban dari kelompoknya.

Model pembelajaran Numbered Head Together dirasa mampu memotivasi siswa dalam permainan bola basket jika dibandingkan dengan pembelajaran yang bersifat konvensional. Menurut Rasana dalam (Luh et al., 2016), Model pembelajaran konvensional merupakan sebuah model pembelajaran ditandai dengan penyajian pengalaman-pengalaman yang berkaitan dengan konsep yang akan dipelajari, dilanjutkan dengan pemberian informasi oleh guru, tanya jawab, pemberian tugas oleh guru, pelaksanaan tugas oleh siswa sampai pada akhirnya guru merasa bahwa apa yang telah diajarkan dimengerti oleh siswa. Dalam pembelajaran konvensional aktivitas siswa dalam pembelajaran masih kurang, guru tidak banyak memberikan kesempatan kepada siswa untuk melaksanakan tanya jawab multi arah. Selain itu penyampaian materi lebih banyak melalui ceramah, tanya jawab, dan penugasan secara terus-menerus.

Penggunaan model pembelajaran yang sesuai dengan pembelajaran dapat mendorong tumbuhnya rasa senang terhadap siswa terhadap pelajaran, menumbuhkan dan meningkatkan motivasi dalam mengerjakan 
5216 Pengaruh Model Pembelajaran Numbered Head Together (NHT) terhadap Motivasi Belajar pada Permainan Bola Basket Siswa SMP - Muhammad Ali Hanafiah, Martiani, Citra Dewi

DOI: https://doi.org/10.31004/edukatif.v3i6.1655

tugas, memberikan kemudahan bagi siswa untuk memahami pelajaran sehingga memungkinkan siswa mencapai hasil belajar yang lebih baik. Sebagaimana sebelumnya sudah kita bahas bersama bahwa ukuran keberhasilan mengajar guru utamanya adalah terletak pada keinginan anak untuk belajar.

\section{METODE PENELITIAN}

Penelitian ini menggunakan pendekatan Kuantitatif, dengan hipotesis komperatif. Jenis penelitian ini adalah Pre-Experimental design karena desain ini belum merupakan eksperimen yang sebenarnya. Hal tersebut dikarenakan masih terdapat variabel luar yang ikut berpengaruh terhadap terbentuknya variabel dependen. Jadi, hasil eksperimen yang merupakan variabel dependen itu bukan semata-mata dipengaruhi oleh variabel indepeden. Hal ini dapat terjadi karena tidak adanya variabel kontrol dan subjek tidak dipilih secara random. Subjek dalam penelitian ini yaitu sebanyak 50 siswa dengan 2 ruang belajar. Teknik pengumpulan data dalam penelitian ini yaitu dengan melaksanakan beberapa tahapan observasi, dokumentasi dan kuisioner (angket). Menurut (Sugiyono, 2014) Kuesioner (Angket) merupakan teknik pengumpulan data yang dilakukan dengn cara memberikan seperangkat pertanyaan dan pernyataan tertulis kepada responden untuk dijawabnya.

Kuesioner merupakan teknik pengumpulan data yang efisien bila peneliti tahu dengan pasti variabel yang akan diukur dan tahu apa yang diharapkan dari responden. Kuesioner dapat berupa pertanyaan/pernyataan terbuka, dapat diberikan kepada responden secara langsung atau dikirim melalui internet. Adapun langkah yang dilkukan setelah menentukan subjek penelitian yaitu: 1) melaksanakan kegiatan pembelajaran dengan bahan ajar dan materi yang sama tetapi menggunakan model pembelajaran yang berbeda yaitu model pembelajaran Numbered Head Together dan pembelajaran konvensional. Petode pengumpulan data yang digunakan yaitu dengan menggunakan metode tes kuisioner. Data yang diperoleh akan dianalisis menggunakan uji statistik.

\section{HASIL PENELITIAN}

Penelitian ini dilakukan dalam 6 kali pertemuan, pada kelas VIIIA menggunakan model pembelajaran Numbered Head Together dan kelas VIII B model pembelajaran konvensional dengan pokok bahasan adalah materi permainan bola basket. Penelitian dilaksanakan pada siswa kelas VIII A (25 orang) dan VIII B (25 orang). Data yang dikumpulkan penulis dalam penelitian yaitu, berupa motivasi belajar siswa saat pembelajaran penjaskes di kelas VIII A dan kelas VIII B. Data hasil Motivasi Belajar Siswa Pada model Pembelajaran Numbered Head Together dan model Pembelajaran Konvensional. (Andriani \& Rasto, 2019) menyatakan dengan adanya motivasi peserta didik dapat merumuskan tujuan dan strategi dalam belajar yang berkaitan dengan keberhasilan mencapai tujuan dalam belajar. Peserta didik yang mempunyai motivasi dalam belajarnya cenderung memperoleh hasil belajar yang maksimal.

Perolehan motivasi belajar saat menggunakan model pembelajaran Numbered Head together pada pembelajaran pendidikan jasmani dengan katagori, tinggi, sedang, dan rendah. Katagori tinggi dengan frekuensi 18, katagori sedang dengan frekuensi 7, sedangakan katagori rendah dengan frekuensi 0. Katagori tinggi dengan frekuensi 18 dan presentase $72 \%$ dapat disimpulkan bahwa dengan menggunakn model pembelajaran Numbered Head Together pada pembelajaran pendidikan jasmani, motivasi belajar siswa dikategorikan dalam kategori tinggi. Perolehan motivasi saat menggunakan model pembelajaran konvensional pada pembelajaran pendidikan jasmani dengan katagori, tinggi, sedang, dan rendah. Katagori tinggi dengan frekuensi 14, katagori sedang dengan frekuensi 11, sedangankan kategori rendah dengan frekuensi 0. Katagori tinggi dengan frekuensi 14 dengan presentase 56\%. Data hasil motivasi belajar siswa pada model pembelajaran numbered head together dan model pembelajaran konvensional, dapat digambarkan pada tabel berikut ini: 
5217 Pengaruh Model Pembelajaran Numbered Head Together (NHT) terhadap Motivasi Belajar pada Permainan Bola Basket Siswa SMP - Muhammad Ali Hanafiah, Martiani, Citra Dewi

DOI: https://doi.org/10.31004/edukatif.v3i6.1655

Tabel 1. Interval Motivasi Belajar

\begin{tabular}{|c|c|c|c|c|c|}
\hline \multirow[t]{2}{*}{ Interval } & \multirow[t]{2}{*}{$\begin{array}{c}\text { Kategori } \\
\text { Motivasi } \\
\text { Belajar }\end{array}$} & \multicolumn{2}{|c|}{$\begin{array}{l}\text { Pembelajaran } \\
\text { Numbered Head } \\
\text { Together }\end{array}$} & \multicolumn{2}{|c|}{$\begin{array}{l}\text { Pembelajaran } \\
\text { Konvensional }\end{array}$} \\
\hline & & $\mathrm{F}$ & $\%$ & $\mathrm{~F}$ & $\%$ \\
\hline $76,00 \leq$ skor angket $\leq 100$ & Tinggi & 18 & $72 \%$ & 14 & $56 \%$ \\
\hline $\begin{array}{l}61,00 \leq \text { skor angket } \leq \\
75.00\end{array}$ & Sedang & 7 & $28 \%$ & 11 & $44 \%$ \\
\hline $0,00 \leq$ skor angket $\leq 60$ & Rendah & 0 & $0 \%$ & 0 & $0 \%$ \\
\hline
\end{tabular}

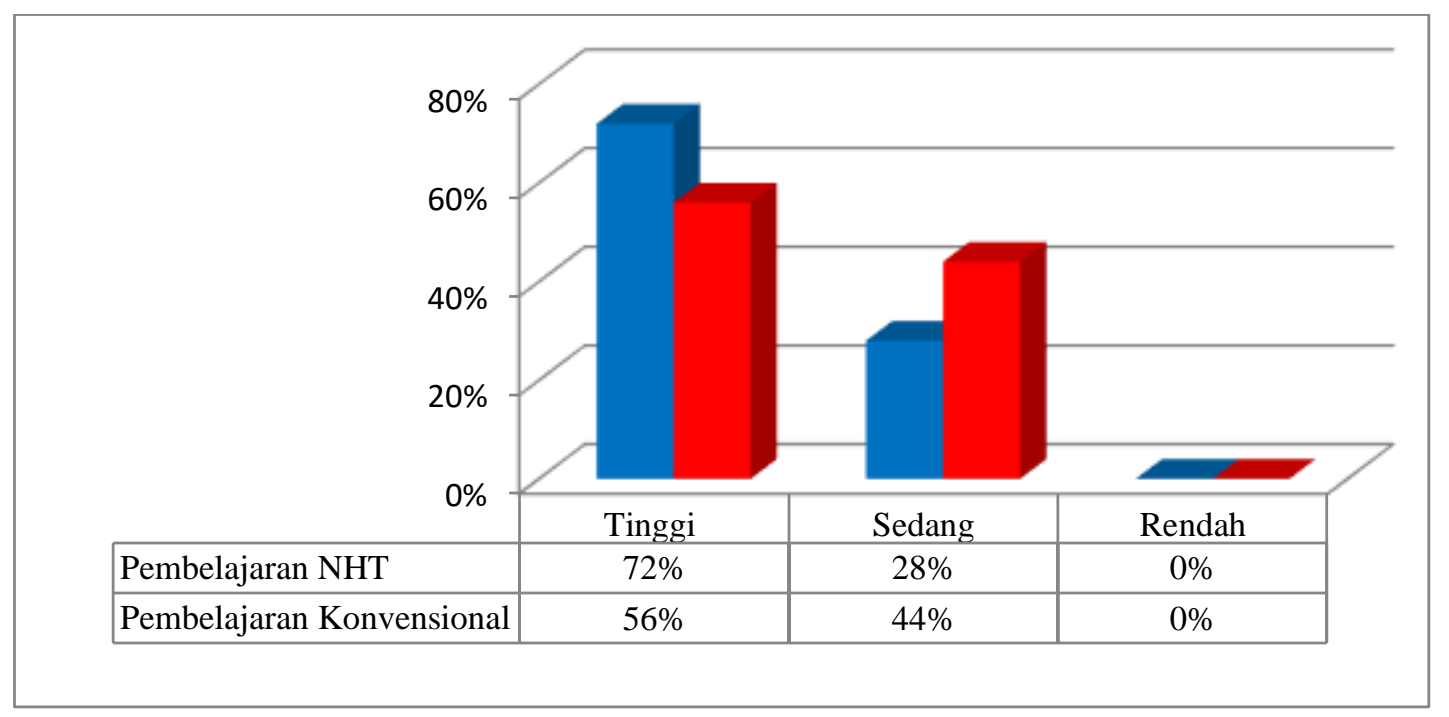

Gambar 1. Diagram Perbandingan Pembelajaran NHT dan Konvensional

Berdasarkan hasil penelitian yang penulis lakukan dapat disimpulkan terdapat perbandingan antara motivasi belajar siswa yang belajar dengan menggunakan model pembelajaran Numbered Head Together (NHT) dengan siswa yang belajar dengan menggunakan model pembelajaran konvensial pada pembelajaran pendidikan jasmani di kelas VIIIA dan VIIIB. Motivasi belajar siswa yang menggunakan model pembelajaran Numbered Head Together (NHT) di kelas VIII A adalah dengan perolehan persentase $72 \%$. Sedangkan motivasi belajar siswa yang menggunakan model pembelajaran konvensional dengan perolehan presentase 56\%. Selanjutnya, berdasarkan hasil uji hipotesis dengan menggunakan uji "t" hitung sebesar 2.554 dengan nilai probabilitas $(\mathrm{sig})=0.017<0.05$, yang berarti hipotesis kerja $\left(\mathrm{H}_{\mathrm{a}}\right)$ dalam penelitian ini diterima, yaitu terdapat perbandingan motivasi belajar siswa kelas VIII A yang menggunakan model pembelajaran Numbered Head Together (NHT) dengan siswa yang belajar dengan menggunakan model pembelajaran konvensional pada pembelajaran Penjaskes. Dimana, pembelajaran yang menggunakan model pembelajaran Numbered Head Together (NHT) motivasinya lebih tinggi dari pada motivasi siswa yang belajar dengan menggunakan model pembelajaran konvensional.

Sulfiani (Sulfiani, 2016) yang mengutarakan bahwa fungsi model pembelajaran Number Head Together (NHT) adalah siswa menjadi lebih aktif dalam proses pembelajaran dan minat siswa yang besar dalam kegiatan pembelajaran akan berpengaruh kepada peningkatan motivasi belajar siswa dan pada akhirnya akan berpengaruh pula terhadap hasil belajar siswa.

Menurut penjabaran di atas, hasil penelitian tersebut sesuai dengan kajian teori yang disampaikan oleh (Trianto, 2010), bahwa model pembelajaran kooperatif tipe Numbered Head Together (NHT) mempengaruhi pola interaksi siswa saat proses belajar mengajar serta mengecek memahaman siswa terhadap isi pelajaran yang disampaikan. Hasil penelitian tersebut juga sebanding dengan penelitian yang dilakukan oleh (Utami et 
5218 Pengaruh Model Pembelajaran Numbered Head Together (NHT) terhadap Motivasi Belajar pada Permainan Bola Basket Siswa SMP - Muhammad Ali Hanafiah, Martiani, Citra Dewi

DOI: https://doi.org/10.31004/edukatif.v3i6.1655

al., 2018), yang diperoleh bahwa model pembelajaran kooperatif tipe Numbered Head Together (NHT) dapat meningkatkan prestasi belajar matematika siswa.

\section{KESIMPULAN}

Kesimpulan dari penjabaran hasil penelitian ini adalah pengaruh motivasi siswa lebih tinggi dengan perolehan persentase $72 \%$ pada penerapan model pembelajaran kooperatif tipe Numbered Head Together (NHT) jika dibandingkan dengan pembelajaran dengan menggunakan model pembelajaran konvensional yaitu dengan perolehan presentase nya 56\% pada pembelajaran pendidikan jasmani. Hal ini dapat dilihat ketika dalam penerapan model pembelajaran kooperatif tipe Numbered Head Together (NHT) akan tetapi aktivitas dan keaktifan siswa dalam proses belajar mengajar di kelas juga ikut meningkat.

\section{DAFTAR PUSTAKA}

Andriani, R., \& Rasto, R. (2019). Motivasi Belajar Sebagai Determinan Hasil Belajar Siswa. Jurnal Pendidikan Manajemen Perkantoran $\quad$ (Jpmanper), $\quad 4(1), \quad 80-86$. Https://Doi.Org/10.17509/JPM.V4I1.14958

Aunurrahman. (2014). Belajar Dan Pembelajaran (Cet. 7). Alfabeta.

Emda, A. (2018). Kedudukan Motivasi Belajar Siswa Dalam Pembelajaran. Lantanida Journal, 5(2), 172. Https://Doi.Org/10.22373/Lj.V5i2.2838

Gracia, A. P., \& Anugraheni, I. (2021). Meta Analisis Model Pembelajaran Kooperatif Tipe Numbered Head Together Terhadap Hasil Belajar Siswa Di Sekolah Dasar. Edukatif: Jurnal Ilmu Pendidikan, 3(2), 436446. Https://Doi.Org/10.31004/Edukatif.V3i2.338

Hamalik, O. (2018). Kurikulum Dan Pembelajaran. Jakarta: Bumi Aksara. Https://Library.Unismuh.Ac.Id/Opac/Detail-Opac?Id=105949

Hutama, P. D., Relmasira, S. C., \& Hardini, A. T. A. (2019). Perbedaan Kemampuan Kolaborasi Dan Hasil Belajar Matematika Siswa Kelas 4 Sd Menggunakan Model Pembelajaran Numbered Head Together Dan Teams Games Tournament. Edukatif: Jurnal Ilmu Pendidikan, 1(2), 80-87. Https://Doi.Org/10.31004/Edukatif.V1i2.11

Khunaini, N., \& Sholikhah, N. (2021). Pengaruh Penggunaan Learning Management System Google Classroom Dan Gaya Mengajar Guru Terhadap Motivasi Belajar Pada Pembelajaran Daring. Edukatif: Jurnal Ilmu Pendidikan, 3(5), 2079-2090.

Kurniawan, D. (2011). Pembelajaran Terpadu: Teori, Praktik, Dan Penilaian. Bandung: CV. Pustaka Cendikia Utama.

Luh, N., Diah, K., Dantes, N., \& Parmiti, D. P. (2016). Pengaruh Model Pembelajaran Numbered Head Together ( NHT ) Terhadap Motivasi Berprestasi Dan Hasil Belajar IPS Pada Siswa Kelas V SD. EJournal PGSD Universitas Pendidikan Ganesha Jurusan, 4(1), 1-10.

Novalinda, E., Kantun, S., \& Widodo, J. (2018). Pengaruh Motivasi Belajar Terhadap Hasil Belajar Mata Pelajaran Akuntansi Siswa Kelas X Jurusan Akuntansi Semester Ganjil Smk Pgri 5 Jember Tahun Pelajaran 2016/2017. Jurnal Pendidikan Ekonomi: Jurnal Ilmiah Ilmu Pendidikan, Ilmu Ekonomi Dan Ilmu Sosial, 11(2), 115. Https://Doi.Org/10.19184/JPE.V11I2.6456

Rahayu, E. T. (2013). Strategi Pembelajaran Pendidikan Jasmani. Bandung: Alfabeta. Https://Cvalfabeta.Com/Product/Strategi-Pembelajaran-Pendidikan-Jasmani/

Saryono, \& Rithaudin, A. (2011). Meta Analisis Pengaruh Pembelajaran Pendekatan Taktik (Tgfu) Terhadap Pengembangan Aspek Kognitif Siswa Dalam Pendidikan Jasmani. Jurnal Pendidikan Jasmani Indonesia, 8(2). Https://Journal.Uny.Ac.Id/Index.Php/Jpji/Article/View/3494 
5219 Pengaruh Model Pembelajaran Numbered Head Together (NHT) terhadap Motivasi Belajar pada Permainan Bola Basket Siswa SMP - Muhammad Ali Hanafiah, Martiani, Citra Dewi DOI: https://doi.org/10.31004/edukatif.v3i6.1655

Sholihah, A., \& Kurniawan, R. Y. (2016). Analisis Pengaruh Motivasi Belajar Dan Lingkungan Belajar Terhadap Hasil Belajar. Jurnal Pendidikan Ekonomi (JUPE). Https://Ejournal.Unesa.Ac.Id/Index.Php/Jupe/Article/View/16008

Sugiyono. (2014). Metode Penelitian Pendidikan Pendekatan Kuantitatif, Kualitatif, Dan R\&D (Cet Ke-19). Bandung: Alfabeta. Https://Docplayer.Info/52782910-Sugiyono-Metode-Penelitian-PendidikanPendekatan-Kuantitatif-Kualitatif-Dan-R-D-Alfabeta-Bandung-Cet-Ke-19-2014-Hlm-3-2.Html

Sulfemi, W. B. (2018). HUBUNGAN MOTIVASI BELAJAR DENGAN HASIL BELAJAR IPS DI SMP KABUPATEN BOGOR. Jurnal Edutecno. Https://Doi.Org/10.5281/ZENODO.2820610

Sulfiani, R. (2016). Penerapan Model Pembelajaran Kooperatif Tipe Numbered Head Together ( NHT ) Untuk Meningkatkan Hasil Belajar Kimia Siswa Kelas XI IPA1 SMA Negeri 3 Watampone ( Studi Pada Materi Pokok Struktur Atom, Sistem Periodik Unsur Dan Bentuk Molekul ). Jurnal Cheremical, 17(1), 1-13. Http://Jurnal.Dharmawangsa.Ac.Id/Index.Php/Almufida/Article/View/63

Suprihatiningrum, J. (2013). Strategi Pembelajaran: Teori \& Aplikasi. Http://Balaiyanpus.Jogjaprov.Go.Id/Opac/Detail-Opac?Id=255613

Trianto. (2010). Model Pembelajaran Terpadu: Konsep, Strategi, Dan Implementasinya Dalam Kurikulum Tingkat Satuan Pendidikan (KTSP). Http://Library.Fis.Uny.Ac.Id/Opac/Index.Php?P=Show_Detail\&Id=1227

Undang-Undang Nomor 20 Tahun 2003 Tentang Sistem Pendidikan Nasional. (2003). In Demographic Research (Vol. 49).

Utami, T., Kristin, F., Anugraheni, I., \& Artikel, R. (2018). Penggunaan Model Pembelajaran Kooperatif Tipe Numbered Head Together (Nht) Pada Pembelajaran Matematika Untuk Meningkatkan Motivasi Belajar Dan Hasil Belajar Siswa Kelas IV. Justek: Jurnal Sains Dan Teknologi, 1(1), 82-88. Https://Doi.Org/10.31764/JUSTEK.V1I1.409 